\title{
Recovery technique using a double scope to rescue failed primary endoscopic ligation
}

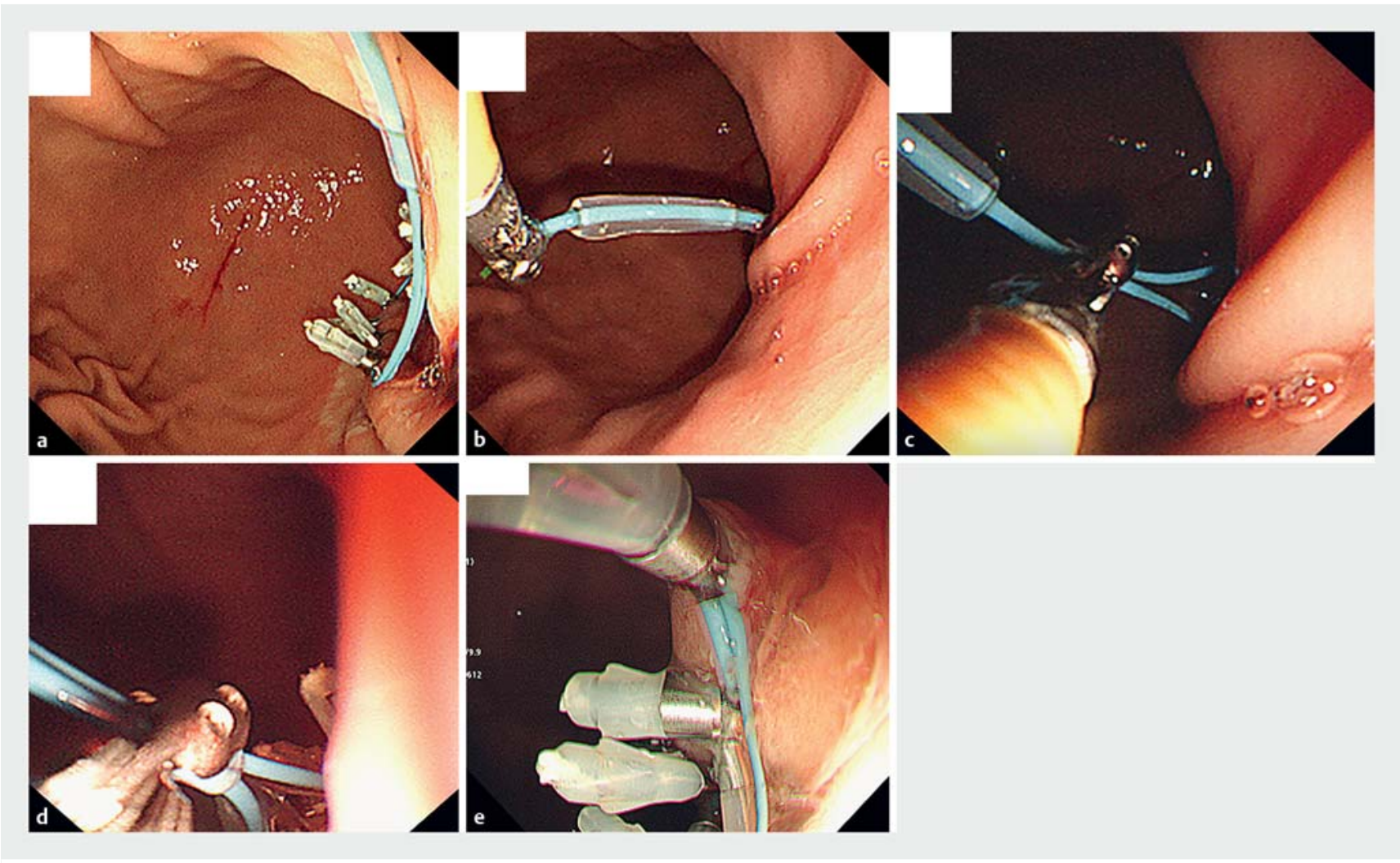

Fig. 1 Recovery technique using a double scope to rescue failed primary endoloop closure. a Endoloop closure in combination with hemoclip application was attempted, but the loop accidentally became detached from the delivery device when tightening the loop. $\mathbf{b}$ The base of the loop was grasped using a forceps with one scope. $\mathbf{c}$ While holding the base with one scope, the stopper was grasped with the other scope. $\mathbf{d}$ The stopper was advanced to tighten the loop appropriately. e A clip was placed to fix the loop to the mucosa, and the closure was completed successfully.

It is important to address the ideal management of artificial large-sized ulcers or perforations, especially those related to endoscopic submucosal dissection (ESD). A few techniques have been described [1 -5]. However, highly advanced endoscopic skills are usually required to achieve complete closure of the defects using standard hemoclips. In contrast, closure using an endoscopic ligation device (ELD) combined with hemoclips allows closure to be achieved relatively easily [1 - 3]. However, we sometimes encounter difficulty when using a combination of endoloop and hemoclips. We therefore propose a recovery technique for cases in which endoloop closure fails ( $>$ Video 1).

A 67-year-old woman underwent an ESD-associated biopsy for submucosal tumor arising from the muscular layer. While closing the procedure-related ulcer using an ELD (Olympus Corp., Tokyo, Japan), something went wrong with the delivery of the ELD, and the loop became detached from the delivery device ( $\vee$ Fig. 1 a). We therefore inserted a double-scope endoscope (XP260; Olympus Corp.). First, we held the base of the loop using the grasping forceps, and then we pulled and fixed the loop on the near side of the ulcer with one scope ( $\triangleright$ Fig. 1 b).
Second, we grasped the stopper of the ELD with the other scope (ฉ Fig.1 c). Third, we gradually advanced the stopper and tightened the loop appropriately ( $>$ Fig.1d). Finally, we placed a clip to fix the loop to the mucosa ( $\triangleright$ Fig. 1 e), and completed the closure successfully.

No complications occurred after this procedure, and the patient was successfully treated. Use of this double-scope technique may be helpful for rescuing failed primary loop closure.

Endoscopy_UCTN_Code_CPL_1AH_2AF 


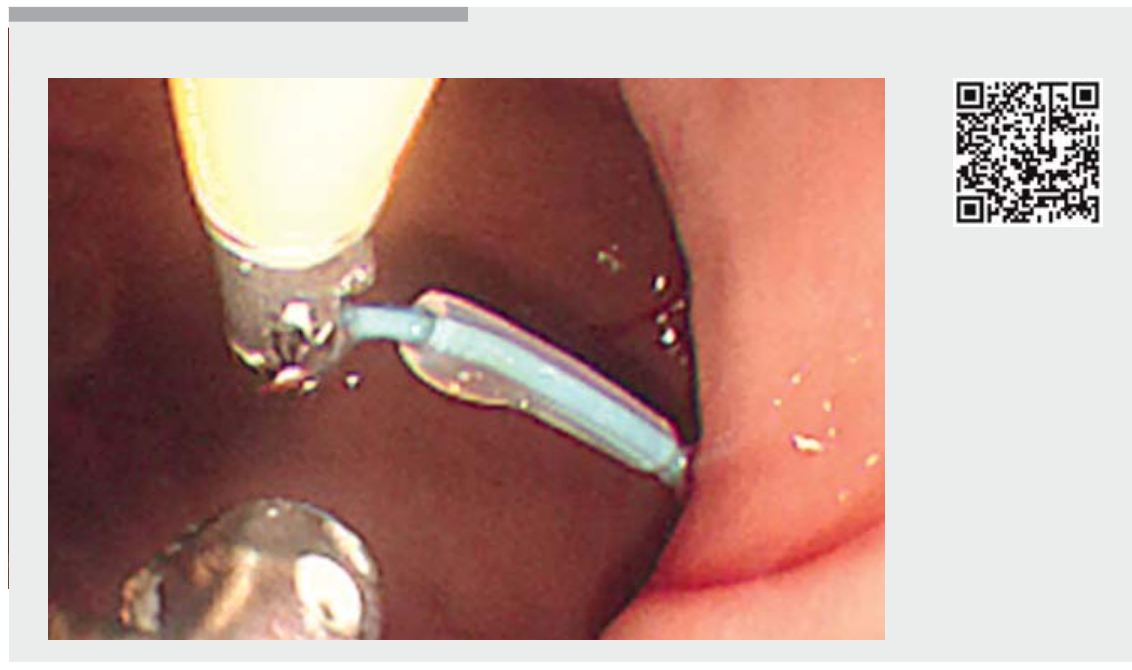

$\checkmark$ Video 1 Steps in the recovery technique using a double scope to rescue failed primary endoscopic ligation.

\section{Competing interests}

None

The authors

Yosuke Minoda, Keishi Komori, Ryoko Naruo, Tsutomu Iwasa, Haruei Ogino, Eikichi Ihara, Yoshihiro Ogawa

Department of Medicine and Bioregulatory Science, Graduate School of Medical Sciences, Kyushu University, Fukuoka, Japan

\section{Corresponding author}

\section{Eikichi Ihara, MD, PhD}

Department of Medicine and Bioregulatory Science, Graduate School of Medical Sciences, Kyushu University, 3-1-1 Maidashi, Higashi-ku, Fukuoka 812-8582, Japan Fax: +81-92-6425287

eikichi@intmed3.med.kyushu-u.ac.jp

\section{References}

[1] Abe S, Oda I, Mori G et al. Complete endoscopic closure of a large gastric defect with endoloop and endoclips after complex endoscopic submucosal dissection. Endoscopy 2015; 47 (Suppl. 01): E374 -E375

[2] Wang J, Wang X, Liu L et al. Endoscopic closure of a colonic defect using a novel endoloop system via a single-channel endoscope. Endoscopy 2016; 48 (Suppl. 01): E142E143

[3] Huang S, Zhu S. Closure of duodenal ulcer perforation using a novel endoloop device with a single-channel gastroscope after failed laparoscopic repair. Endoscopy 2017; 49: E31-E32

[4] Nishiyama N, Mori H, Rafiq K et al. Over-thescope clip system is effective for the closure of post-endoscopic submucosal dissection ulcer, especially at the greater curvature. Endoscopy 2014; 46 (Suppl. 01): E130 E131

[5] Choi KD, Jung HY, Lee GH et al. Application of metal hemoclips for closure of endoscopic mucosal resection-induced ulcers of the stomach to prevent delayed bleeding. Surg Endosc 2008; 22: 1882 - 1886

\section{Bibliography}

DOI https://doi.org/10.1055/a-0631-7760

Published online: 19.6.2018

Endoscopy 2018; 50: E244-E245

(c) Georg Thieme Verlag KG

Stuttgart · New York

ISSN 0013-726X

\section{ENDOSCOPY E-VIDEOS}

https://eref.thieme.de/e-videos

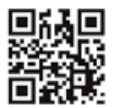

Endoscopy E-Videos is a free access online section, reporting on interesting cases and new techniques in gastroenterological endoscopy. All papers include a high quality video and all contributions are freely accessible online.

This section has its own submission website at https://mc.manuscriptcentral.com/e-videos 